\title{
The role of radiation damping in the modeling of repeated earthquake events
}

\author{
Paola Crupi ${ }^{1}$, Andrea Bizzarri ${ }^{2,{ }^{\star}}$ \\ ${ }^{1}$ Università degli Studi di Bari, Dipartimento di Scienze della Terra e Geoambientali, Bari, Italy \\ ${ }^{2}$ Istituto Nazionale di Geofisica e Vulcanologia, Sezione di Bologna, Bologna, Italy
}

\section{Article history}

Received September 5, 2012; accepted January 28, 2013.

Subject classification:

Seismic cycle, Earthquake recurrence, Radiation damping, Spring-slider model, Fault rheology, Computational seismology.

\begin{abstract}
We have investigated the role of the radiation damping term (RDT) on repeated earthquake ruptures by modeling the faulting process through a single one-dimensional analog fault system governed by different constitutive laws. The RDT expresses the energy lost by the seismic waves. The RDT is inherently accounted for in more elaborated, fully dynamic models of extended fault, whereas it is neglected in one-dimensional fault models. In this study, we adopt various formulations of the laboratoryderived rate-dependent and state-dependent friction constitutive laws: the Dieterich-Ruina law, the Ruina-Dieterich law and the Chester and Higgs law. Our numerical results clearly indicate that the RDT significantly affects the system dynamics. More specifically, the more the RDT is effective, the more frequent the slip failures are (with a cycle-time reduction of ca. 30\%). We also show that inclusion of the RDT tends to promote smaller but more frequent earthquake instabilities, irrespective of the choice of the governing law. Our data shed light on the limitations implied by the conventional formulation of the equation of motion for the spring system, in which the energy radiation is ignored.
\end{abstract}

\section{Introduction}

One of the challenges of natural-hazard reduction and earthquake-risk mitigation is the need to understand the recurrence interval in seismic instability events. Plate tectonics provide the theoretical background that is required to identify at least some of the specific seismic source regions where earthquakes have occurred in the past [Allen 2007]. However, it is still difficult to predict large earthquakes, due to their complex occurrence patterns [Abe and Kato 2012]. Scientists have been trying to understand the earthquake machine and the chemical and physical processes controlling it (as well as their complicated feedback and unknown parameters) from different points of view and with different approaches [Panza et al. 2001, Bizzarri 2011, Panza et al. 2011, Bizzarri 2012d, Wyss et al. 2012]. The relationships between the frequencies of earthquakes and their different seismic moments - expressed in terms of the slip rate on a fault - is a possible approach to the study of the seismic activity that is likely to occur in a specific region [Molnar 1979, Allen 2007]. Nevertheless, this assessment approach usually starts from the existing historical seismicity records, and many seismologists agree that the seismic records available are often not extensive enough to provide reliable assessment of earthquake frequency in a settled area [e.g., Molnar 1979]. Indeed, data collection ranging from $10^{3}-10^{4}$ years might be required to determine, with reasonable confidence, a possible earthquake recurrence interval in regions with high seismic-motion variability [Molnar 1979]. Consequently, further methods of investigation are required to provide a broader insight into seismicity recurrence. This emphasizes the importance of numerical model simulations, which are a powerful tool to explore the complex physical conditions behind earthquake cycles and the occurrence of unstable slip episodes.

In the ideal case where no remote events perturb the state of a given fault system, the elastic rebound theory [Reid 1910] remains the basis of our understanding of the earthquake cycle, and this postulates that once the stress in a region exceeds some strength value, a rupture occurs. Several physical models have been proposed to describe the properties of the earthquake cycle, among which there is the springslider system (namely, a harmonic oscillator), which can reproduce the seismic instability periodical patterns and the so-called stick-slip mechanism observed in laboratory experiments [Bizzarri et al. 2011, and references therein].

In this study, we focus on the temporal evolution of the frictional properties of faults. More specifically, we present and discuss numerical experiments that are conducted using a mass-spring model, to explore how the radiation damping term (RDT) can affect the phenomenology of earthquake faulting and the seismic cycle of faults, through obeying different governing laws: i.e., the Dieterich-Ruina (DR) law [Dieterich 1979]; the Ruina-Dieterich (RD) law [Ruina 1983]; and the Chester and Higgs (CH) law [Chester and Higgs 1992]. 
From a physical point of view, the radiation damping approximation [Rice 1993] mimics the energy lost due to seismic-wave propagation. While this factor is inherently assumed in more elaborate fault models (such as continuum, three-dimensional [3-D] fault models), it is frequently ignored in the simplistic one-degree-of-freedom mass-spring dashpot model (to date, relevant exceptions are $\mathrm{Xu}$ and Knopoff [1994], Beeler [2001, 2006], and Bizzarri [2012a]). Furthermore, we have seen that its inclusion within spring-slider dynamics leads to interesting results, which are widely illustrated within the next applicative sections. The novelty of the present study is that it is a systematic study of the effects on the analog fault dynamics that result from the introduction of the radiation damping factor, a concept as yet unexplored in previous studies (Xu and Knopoff [1994] and Beeler [2001] did not consider rate and state friction, while Bizzarri [2012a] considered only one single configuration with the RD law and did not consider the effects of the RDT in the context of earthquake recurrence).

\section{Modeling of the seismic cycle with the mass-spring system}

\subsection{The spring-slider model}

In this study, we consider the widely used 1-D fault model known as the spring-slider system (or the mass-spring system; see figure 1 in Belardinelli et al. [2003]), in which a fault is modeled as a point of mass $m$ (per unit surface area) that slides over a plane against a shear stress $\tau$ and subject to a normal load $\sigma_{n}^{\text {eff }}$ (e.g., see Rice and Tse [1986], among many others). The system is loaded by a remote velocity $\mathrm{v}_{\text {load }}$ that acts through the end of the spring on the block, which physically represents the velocity of a tectonic plate acting on a potentially seismogenic structure that is to be modeled. For the sake of simplicity, we will assume here that $\sigma_{n}^{\text {eff }}$ is constant over the whole faulting process; the possible variations in effective normal stress and other seismological implications have been quantitatively discussed elsewhere [Bizzarri and Cocco 2006a, Bizzarri and Cocco 2006b, Bizzarri 2010b, Bizzarri 2012c].

The spring-slider system equation of motion is a firstorder partial differential equation that describes a harmonic oscillator (see also Bizzarri [2012d]):

$$
\dot{\mathbf{U}} \equiv \mathbf{F}(\mathbf{U}, t)
$$

where:

with:

$$
\mathbf{U} \equiv\left[\begin{array}{l}
u \\
v
\end{array}\right] \text { and } \mathbf{F} \equiv\left[\frac{1}{m} f(u, v, t)\right]
$$

$v \equiv \dot{u}$ and $f(u, v, t) \equiv k v_{\text {load }} t-k u(t)-\tau-c v(t)$.

In Equations (1), (2) and (3) (see also Equation 2 in Beeler [2001], or equation 2 in Beeler et al. [2002]), the overdot indi- cates the time derivative, $u$ is the block displacement, $v$ is its velocity, and $t$ is the time. The fault stiffness $k$, which mimics the interactions with the elastic medium surrounding the fault, can be associated with the static stress drop and the total slip that develops during a failure event [Walsh 1971].

The shear stress $\tau$ expresses the fault governing law, as described in Section 2.2. The last term in Equation (3) defines the so-called RDT, in which constant $\mathrm{c}$ depends on the parameters of the medium where the fault is embedded [Rice 1993]:

$$
c \equiv \frac{G}{2 v_{S}}
$$

where $G$ is the elastic medium rigidity, and $v_{S}$ is the $S$-wave velocity away from the fault plane. The RDT simulates the energy that is lost during the sliding phase, in terms of propagating seismic waves, and moreover, it reduces the shear stress on the fault plane by an amount that is directly proportional to the slip velocity [Rice 1993, Kato and Tullis 2001, see also Brune 1970]. In other words, the RDT defines how the local fault impedance relates the slip velocities to the stress, as a (1-D) strain wave propagates into the host rock [Rubin and Ampuero 2005]. Indeed, Equation (3) is a proxy of the true behavior of an extended fault that is embedded in a continuous medium, and it is deemed valid in the case of a fault with homogeneous properties.

In the case of the Rice [1993] simulation of a continuum medium with rate-dependent and state-dependent friction, is it possible to either perform a fully dynamic simulation or use the radiation damping approximation. Without one or the other, the fault-slip velocities with rate-weakening are unbounded, and the model will blow up. On the contrary, such bounding is not needed for a spring-slider model that accounts for inertia; nonetheless, it allows for a more earthquake-like analog model. Indeed, the use of the RDT in the slider-block equation is just a way to produce a simulation that has radiated energy loss. If we perform a spring-slider simulation with inertia alone, no radiation effects will be observed, and a complete overshoot will also result (by overshoot, we refer to the further traction drop that occurs in the decelerating phase of the system, during which the block decelerates due to the spring compression; see Rice and Tse [1986]). This behavior, however, is not consistent with natural earthquakes, or likely to occur with laboratory stick-slip experiments (no radiated energy is the complete overshoot condition).

Moreover, we also emphasize that the use of the RDT with inertia does not duplicate the rate dependence contained in the rate and state laws, as the explicit dependence of the velocity in the expression of frictional resistance and in the RDT has the opposite sign. Finally, we mention that if, on the other hand, a numerical simulation of a slider block with radiation damping and no inertia is performed (as in Segall [2010]), the result is zero overshoot. While this is a 
good analog model of the Orowan condition [Orowan 1960] (see also Gibowicz [1998]), which has often been used by Kanamori to analyze earthquakes, it is generally still not consistent with natural earthquakes.

The energy lost in the form of propagating seismic waves represented by the RDT is essentially assumed to be due to planar waves [Rice 1993]. The particular choice made in Equation (4) then states that all radiation results from shear waves.

In Equation (1), $\mathbf{U}$ formally defines the system state at a generic time $t$, in the conventional phase space $(u, v)$. Despite its obvious limitations in reproducing a fault system, either owing to its own finite size or to its being a single-degree-offreedom dynamic system [Gu et al. 1984, Carlson et al. 1994, Bizzarri et al. 2011, among others], the spring-mass model has provided crucial insight into repeated seismic events.

\subsection{Governing equations}

Stick-slip motion results from the interactions between an elastic system and a frictionally slipping surface [Brace and Byerlee 1966, Gu et al. 1984]. Several attempts have been made to find a realistic and adequate expression of a faultgoverning law [e.g., Dieterich 1978, Dieterich 1979, Ruina 1983, Chester and Higgs 1992]. Despite the advances in laboratory settings, we are still far from the formulation of a universal constitutive model for real-world faults (see discussions in Bizzarri and Cocco [2006c] and Bizzarri [2011]). A wide class of earthquake source studies has been based upon the rate-dependent and state-dependent (RS) friction laws, in which the shear stress $\tau$ depends on the slip rate $\mathrm{v}$ and on a state variable $\Psi$ (see Bizzarri [2011] for a detailed review). In the present study, we adopt the following formulations of the laboratory-derived RS friction law models:

$$
\begin{gathered}
\left\{\begin{array}{c}
{\left[\mu_{*}+a \ln \left(\frac{v}{v_{*}}\right)+b \ln \left(\frac{\Psi v_{*}}{L}\right)\right] \sigma_{n}^{\text {eff }}} \\
\frac{d}{d t} \Psi=1-\frac{\Psi v}{L}
\end{array}\right. \\
\left\{\begin{array}{c}
{\left[\mu_{*}+a \ln \left(\frac{v}{v_{*}}\right)+b \ln \left(\frac{\Psi v_{*}}{L}\right)\right] \sigma_{n}^{\text {eff }}} \\
\frac{d}{d t} \Psi=1-\frac{\Psi v}{L} \ln \left(\frac{\Psi v}{L}\right)
\end{array}\right. \\
\left\{\begin{array}{c}
{\left[\mu_{*}+a \ln \left(\frac{v}{v_{*}}\right)+b \ln \left(\frac{\Psi v_{*}}{L}\right)+a \frac{Q_{a}}{R}\left(\frac{1}{T}-\frac{1}{T_{*}}\right)\right] \sigma_{n}^{\text {eff }}} \\
\frac{d}{d t} \Psi=-\frac{\Psi v}{L}\left[\ln \left(\frac{\Psi v}{L}\right)+\frac{Q_{b}}{R}\left(\frac{1}{T}-\frac{1}{T_{*}}\right)\right]
\end{array}\right.
\end{gathered}
$$

where $\mu_{*}$ and $v_{*}$ are a reference friction coefficient and a reference velocity, respectively, $a$ and $b$ are experimental constitutive parameters that express the direct and evolution effects, respectively, of friction, and $L$ is the characteristic distance for the state variable evolution. Moreover, $\sigma_{n}^{\text {eff }}$ is the effective normal stress, $R$ is the universal gas constant, $Q_{a}$ and $Q_{b}$ are ap- parent activation energies pertaining to the direct and evolution effects, respectively, $T_{*}$ is a reference temperature, and $T$ is the temperature developed from frictional heating. This last quantity, $T$, is computed as follows [Bizzarri et al. 2011]:

$$
\begin{aligned}
& T= \\
& T_{0}+\frac{1}{\rho S \sqrt{\pi \kappa}} \sum_{m=1}^{n} \tau^{(m)} v^{(m)}\left(\sqrt{t-t^{(m-1)}}-\sqrt{t-t^{(m)}}\right)
\end{aligned}
$$

In Equation (8), $T_{0}$ is the initial uniform temperature (i.e., at $t=0$ ), $\rho$ is the cubic mass density of the rock, $S$ is the specific heat, $\kappa$ is the thermal diffusivity of the continuous medium in which the fault is embedded, the apex $m$ denotes the discrete time, and $t^{(0)}=0$ and $t^{(n)}=t$.

Equations (6) and (7) are the RD and $\mathrm{CH}$ laws, respectively, that are derived from the DR law (Equation 5), where the state variable physically represents the average contact time of the sliding surface micro contacts [Bizzarri 2011]. It is clear from Equations (5) to (7) that $\tau$, which appears in Equation (3), can be written (with the standard abuse of notations) as $\tau=\tau(v(t), \Psi(t))$. The initial state of the system is given by $\mathbf{U}_{\mathbf{0}}=\left[\begin{array}{c}u_{0} \\ v_{0}\end{array}\right]$, and the corresponding shear stress is $\tau_{0}=\tau^{s S}\left(v_{0}\right)$; i.e., the steady-state, which is achieved when $\Psi$ $=0$ in Equations (5) to (7).

\subsection{Simulation strategy}

In the present study, we numerically solve a system of differential equations that is composed of an equation of motion (Equation 3) that is combined with one of the three constitutive laws (Equations 5, 6 or 7). The system of equations is solved by adopting the Runge-Kutta temporal integration technique with adaptive step-size control [Press et al. 1992].

In line with the simulation strategy widely used and described by Boatwright and Cocco [1996] and Belardinelli et al. [2003], in the present study, the slider equation of motion (Equation 3) is solved quasi-statically for relatively low sliding velocities, and dynamically for high sliding velocities. The threshold that marks the limit between these two sliding regimes is the critical velocity $v_{c}$, the reference value of which is assumed to be $0.1 \mathrm{~mm} / \mathrm{s}$ in the present study (according to Belardinelli et al. [2003], and references therein). Moreover, as previously discussed by Weeks [1993], we assume that the steady-state friction becomes independent of $v$ at sliding velocities that exceed the critical value $v_{c}$; this entails considering $a \ln \left(v_{c} / v_{*}\right)$ instead of $a \ln \left(v / v_{*}\right)$ at high sliding velocities (namely, for $v>v_{c}$; see [Weeks 1993, Boatwright and Cocco 1996, Belardinelli et al. 2003]). This formulation is known as the frozen approximation of the RS friction laws.

First, we simulate the spring-slider evolution by using all of the three constitutive laws (the DR, $\mathrm{RD}$ and $\mathrm{CH}$ laws) with and without the inclusion of the RDT in the equation of motion (Equation 3). Subsequently, we compare the numerical results, to highlight the influence potentially exerted 


\section{Configuration A}

\section{Model parameters}

Loading velocity, $v_{\text {load }}$

Machine stiffness, $k$

$3.17 \times 10^{-10} \mathrm{~m} / \mathrm{s}$

$10 \mathrm{MPa} / \mathrm{m}$

$3.17 \times 10^{-3} \mathrm{~Pa} / \mathrm{s}$

$5 \mathrm{~s}$

$$
\begin{gathered}
4.5 \mathrm{MPa} \mathrm{s} / \mathrm{m} \\
10^{-4} \mathrm{~m} / \mathrm{s} \\
10^{-1} \mathrm{~m} / \mathrm{s}
\end{gathered}
$$

$3.17 \times 10^{-10} \mathrm{~m} / \mathrm{s}$

$10 \mathrm{MPa} / \mathrm{m}$

$3.17 \times 10^{-3} \mathrm{~Pa} / \mathrm{s}$

$5 \mathrm{~s}$

Threshold velocity defining seismic instability, $v_{l}$

Fault constitutive parameters

Effective normal stress, $\sigma_{n}^{\text {eff }}$

$30 \mathrm{MPa}$

Initial slip velocity, $v_{0}$

Initial shear stress, $\tau_{0}$

Initial temperature, $T_{0}$

Logarithmic direct effect parameter, $a$

Evolution effect parameter, $b$

$3.17 \times 10^{-10} \mathrm{~m} / \mathrm{s}\left(=v_{\text {load }}\right)$

$16.8 \mathrm{MPa}\left(=\mu_{*} \sigma_{n}^{\text {eff }}\right)$

$210^{\circ} \mathrm{C}$

0.008

0.016

$0.01 \mathrm{~m}$

0.56

$3.17 \times 10^{-10} \mathrm{~m} / \mathrm{s}\left(=v_{0}\right)$

$210{ }^{\circ} \mathrm{C}\left(=T_{0}\right)$
$30 \mathrm{MPa}$

$$
\begin{gathered}
3.17 \times 10^{-10} \mathrm{~m} / \mathrm{s}\left(=v_{\text {load }}\right) \\
16.8 \mathrm{MPa}\left(=\mu_{*} \sigma_{n}^{\text {eff }}\right) \\
210^{\circ} \mathrm{C} \\
0.012 \\
0.016 \\
0.01 \mathrm{~m} \\
0.56 \\
3.17 \times 10^{-10} \mathrm{~m} / \mathrm{s}\left(=v_{0}\right) \\
210^{\circ} \mathrm{C}\left(=T_{0}\right)
\end{gathered}
$$

Table 1. Parameters adopted in the present study. Both configurations are velocity weakening regimes, but Configuration A (with $b=2 a$ ) represents a more unstable fault with respect to Configuration B.

Next page. /Top: Figure 1. Comparisons between the numerical simulations for the DR law (Equation 5) without and with the RDT (thick and thin lines, respectively). (a) Time evolution of displacement. (b) Slip velocity history on a logarithmic scale. (c) Time history of the temperature developed by frictional heating, computed as in Equation (3) by Bizzarri [2010c], which is known to represent an upper bounds of the frictional heating. $\Delta \mathrm{T}$ represents the difference between the temperature computed at the present time step and the initial temperature, which in this case also equals the reference temperature (see Table 1). (d) Phase diagram; i.e., normalized stress versus dimensionless slip velocity. The quantity $A$ is defined as $A=a \sigma_{n}^{e f f}$. The vertical black line represents $\ln \left(v_{c} / v_{*}\right)$, which is the threshold between the quasi-static and the full dynamic regimes (see Section 2.3 for numerical details). The parameters are listed in Table 1. Red curves, Configuration A; blue curves, Configuration B. / Bottom: Figure 2. As for Figure 1, here related to the RD law (Equation 6).

by the radiation damping approximation on the seismic cycle evolution, and consequently, on the recurrence time in seismic instabilities that are governed by the different constitutive laws. Next, we perform further simulations with the $\mathrm{CH}$ constitutive law only, and use Table 1, Configuration A by varying the $v_{c}$, so as to focus on the role that their different magnitudes can have in seismic-cycle evolution.

\section{Numerical results}

\subsection{The RDT influence: a stable behavior irrespective of the} choice of the governing law

In this section, we aim to analyze the time evolution of a spring-slider system that obeys three different constitutive laws (the DR, RD and $\mathrm{CH}$ laws; see Section 2.2). More specifically, earthquake recurrence tends to be markedly affected by the nonobvious choice of the fault constitutive law [e.g., Bizzarri et al. 2011]. In the present study, we present and discuss several numerical results that illustrate a set of further effects of different radiation damping coefficient values, and of critical velocity (see Table 3 ) on controlling the temporal evolution of repeated earthquake ruptures.

The comparisons will initially be conducted by running simulations without and with the inclusion of the RDT, and through a selection of the initial set parameters from both Configurations A and B, as reported in Table 1. Although both of these configurations are velocity-weakening regimes (which explains the difference $b-a>0$ ), Configuration $A$ is more unstable than Configuration B because $b=2 a$ (this defines a strong seismic regime, as per the terminology of Boatwright and Cocco [1996]). The results are reported in Figures 1 (the DR law), 2 (the RD law) and 3 (the $\mathrm{CH}$ law). More specifically, the red lines in Figures 1-3 pertain to Configuration $\mathrm{A}$, and the blue lines refer to Configuration $\mathrm{B}$. 


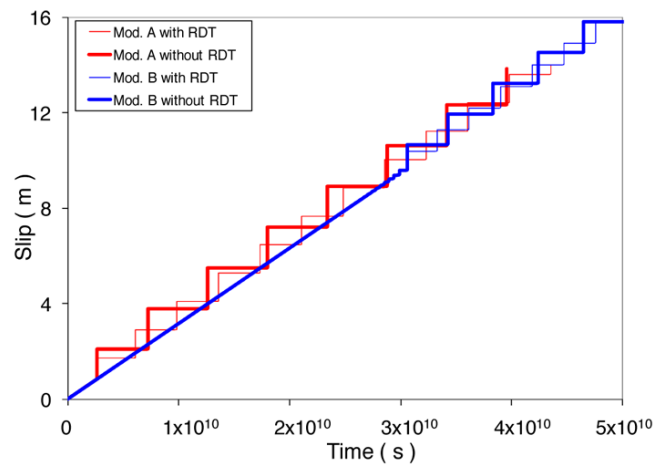

(a)

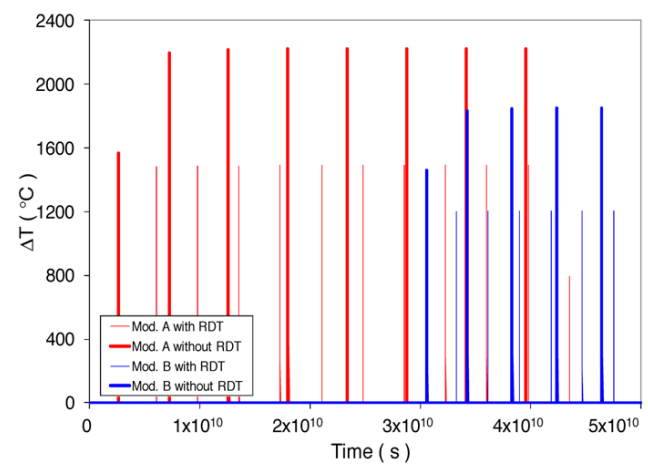

(c)

Figure 1 (caption on previous page).

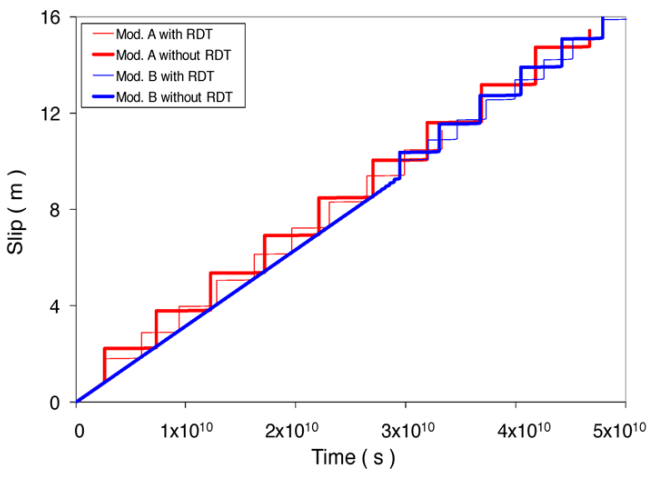

(a)

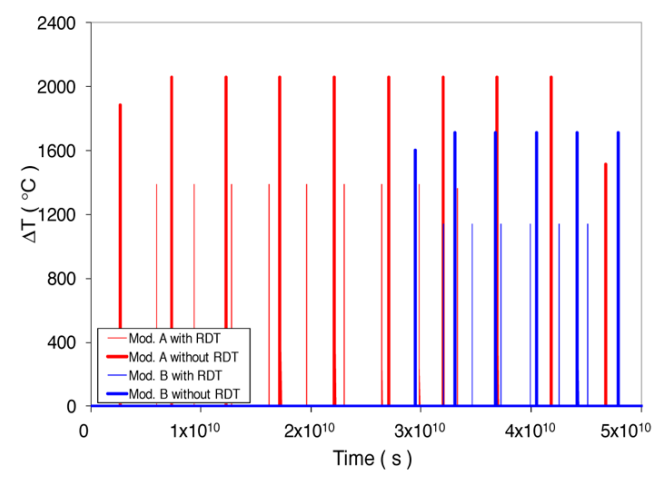

(c)

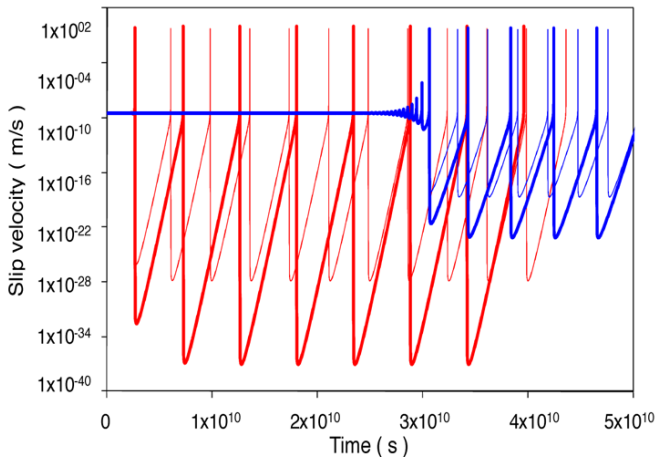

(b)

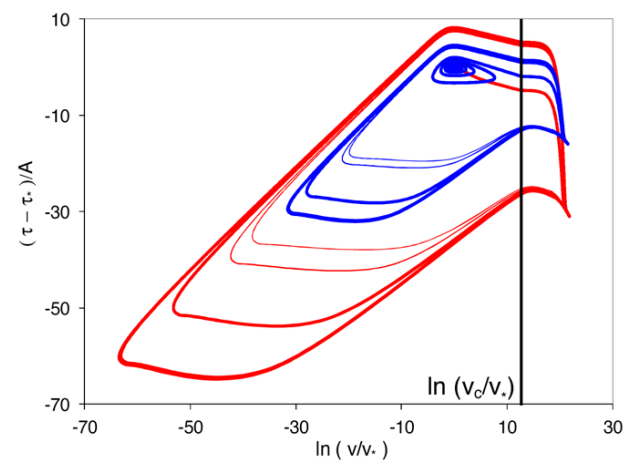

(d)

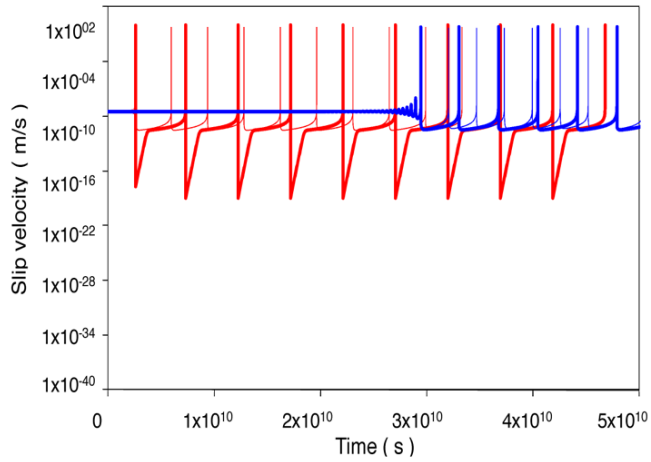

(b)

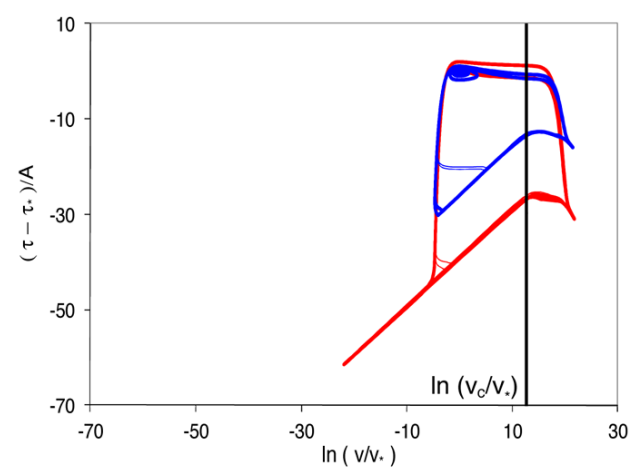

(d)

Figure 2 (caption on previous page). 


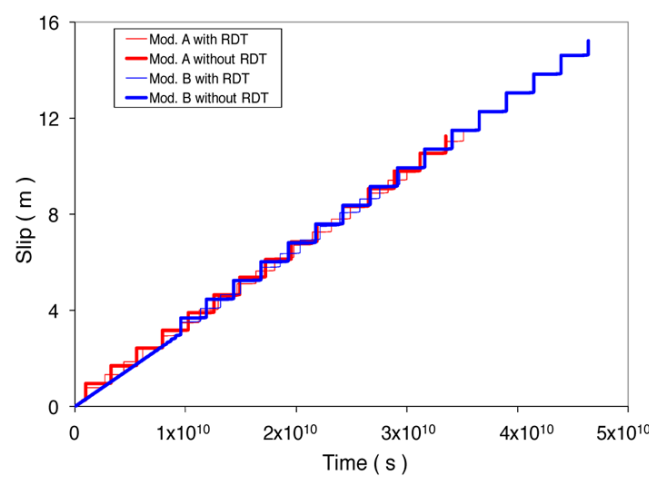

(a)

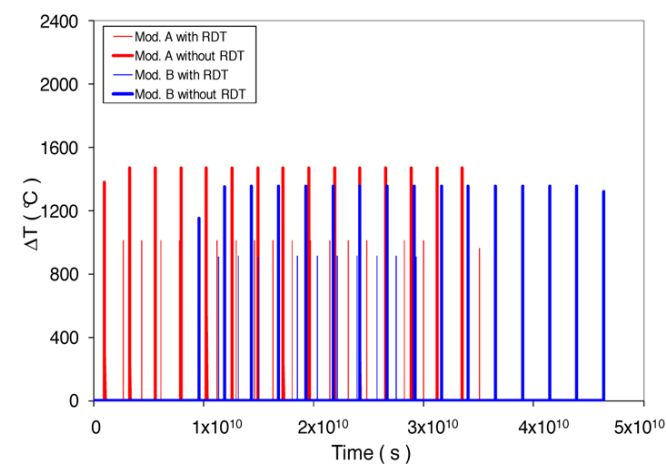

(c)

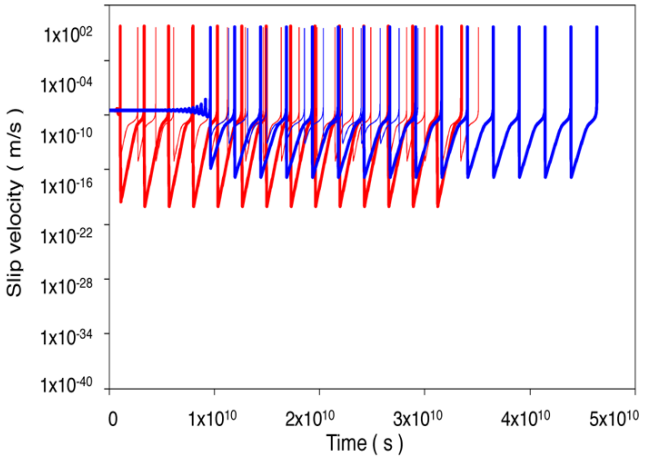

(b)

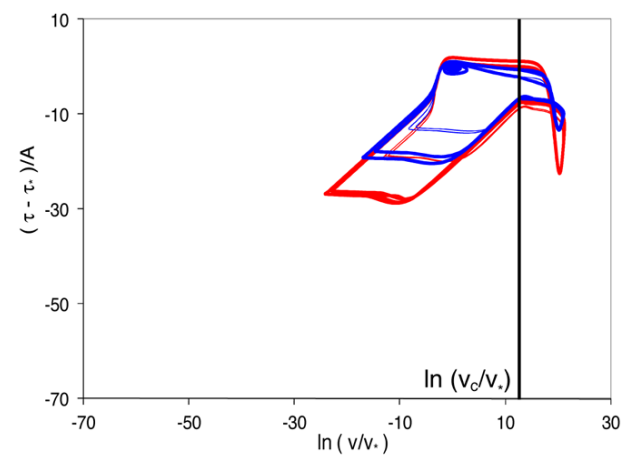

(d)

Figure 3. As for Figure 1, here related to the $\mathrm{CH}$ law (Equation 7).

\begin{tabular}{|c|c|c|c|c|c|c|}
\hline \multirow[t]{3}{*}{ Governing law } & \multicolumn{6}{|c|}{ Recurrence time } \\
\hline & \multicolumn{3}{|c|}{ Configuration A } & \multicolumn{3}{|c|}{ Configuration B } \\
\hline & $\begin{array}{c}\text { Without } \\
\text { RDT } \\
\text { (years) }\end{array}$ & $\begin{array}{l}\text { With } \\
\text { RDT } \\
\text { (years) }\end{array}$ & $\begin{array}{c}\text { RDT } \\
\text { difference } \\
(\%)\end{array}$ & $\begin{array}{c}\text { Without } \\
\text { RDT } \\
\text { (years) }\end{array}$ & $\begin{array}{l}\text { With } \\
\text { RDT } \\
\text { (years) }\end{array}$ & $\begin{array}{c}\text { RDT } \\
\text { difference } \\
(\%)\end{array}$ \\
\hline $\begin{array}{l}\text { Dieterich-Ruina } \\
\text { (Figure 1) }\end{array}$ & 170.1 & 118.6 & 30.3 & 128.8 & 90.3 & 29.9 \\
\hline $\begin{array}{l}\text { Ruina-Dieterich } \\
\text { (Figure 2) }\end{array}$ & 156.3 & 108.3 & 30.7 & 117.8 & 83.3 & 29.3 \\
\hline $\begin{array}{l}\text { Chester and Higgs } \\
\text { (Figure 3) }\end{array}$ & 73.7 & 54.02 & 26.7 & 78.05 & 57.01 & 26.9 \\
\hline
\end{tabular}

Table 2. Recurrence times for the different governing laws and the two configurations listed in Table 1. The last row in the table reports the cycle time variation, computed as:

$$
\Delta T_{\text {cycle }}=100 \frac{T_{\text {cycle }}^{(\text {without RDT })}-T_{\text {cycle }}^{(\text {with RDT })}}{T_{\text {cycle }}^{(\text {without RDT })}} .
$$

Moreover, the thick lines refer to the simulations without the RDT, and the thin lines refer to the RDT-aided simulations.

Interestingly, if we consider the RDT simulations (Figures $1-3$, thin lines), we can appreciate that the inclusion of such an approximation in the equation of motion (Equation 3 ) has several important effects on the evolution of the system (in what follows, we will focus on the DR law model, as the results discussed are qualitatively the same for the $\mathrm{RD}$ law and $\mathrm{CH}$ law simulations). As an example, for Configurations A and $\mathrm{B}$, the slip developed during each seismic instability event is smaller than the slip where the RDT approximation has not been accounted for (see Figure 1a). Similarly, the velocity peaks reach a lower value in the RDT case, compared to the reference case without RDT (see Figure 1b). Moreover, the temperatures that result from the frictional heating are lower with the adoption of the RDT term (see Figure 1c). Figure 1d reports the phase diagram, which illustrates that the dynamic stress drop, which occurs within the close-to-failure accelerating phase, is the same in both cases, so without and with the RDT (Figure 1d, thick and thin lines, respectively). On the contrary, the dynamic overshoot 


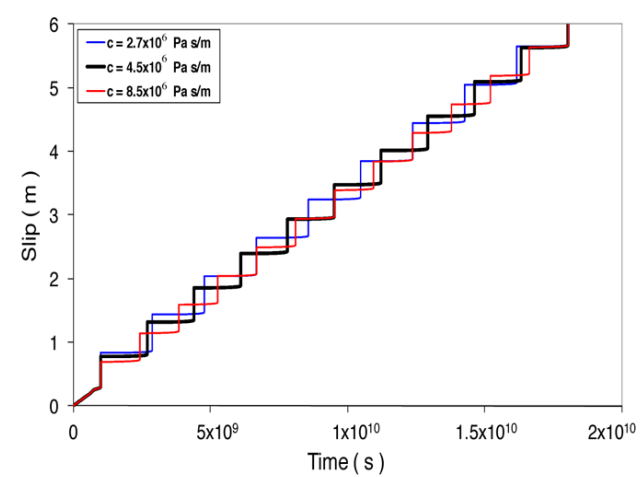

(a)

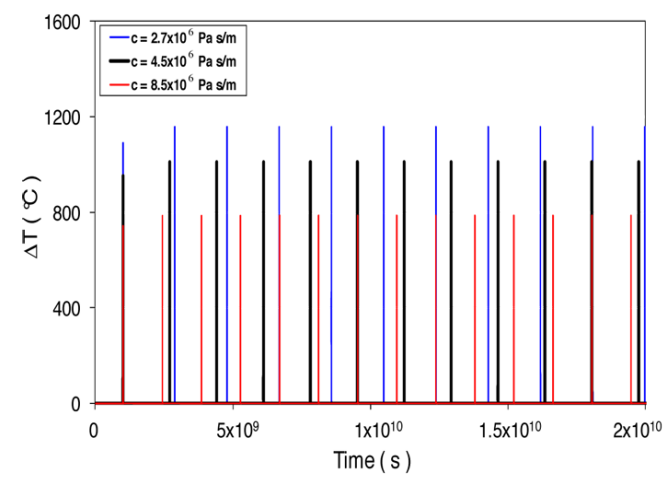

(c)

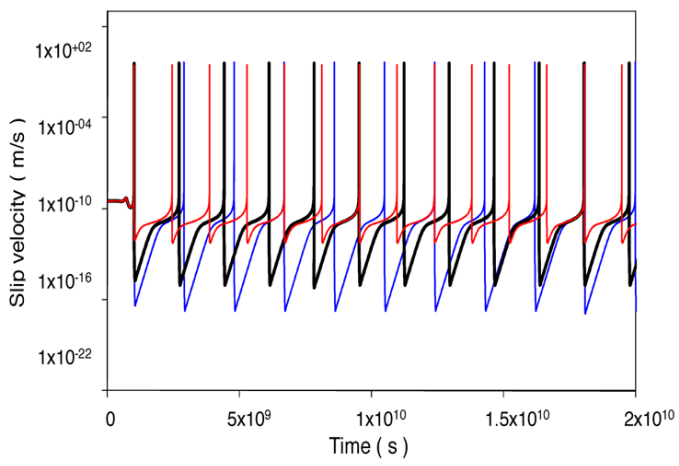

(b)

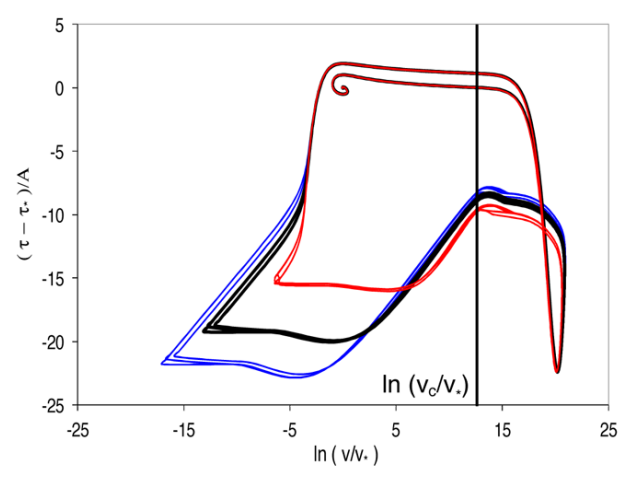

(d)

Figure 4. Comparisons between the numerical simulations for the $\mathrm{CH}$ law (Equation 7) with RDT for Configuration A, using different values of $c$ (the radiation damping coefficient from Equation 3) at the reference value of $v_{c}$. (a) Slip displacement versus time. (b) Time history of the slip velocity (on a logarithmic scale). (c) Time history of the temperature developed by frictional heating. (d) Phase portrait. Black, reference configuration (see Table 1).

is rather different. Indeed, the dynamic overshoot is larger in the case without RDT, and this difference explains why the seismic cycle is so different if the RDT is considered or neglected. In particular, by adding the RDT, there is a reduction in the dynamic overshoot of ca. $44 \%$. This result is in agreement with previous estimates [McGarr 1994, 1999; see also Beeler 2001].

In all of the simulations, the seismic cycle that result from the RDT inclusion is shorter than the cycle calculated for the models that do not include the RDT (Table 2). Consequently, all of the observations made so far show that if we consider a spring-slider system that includes the RDT, it will take less time to reach a new instability phase, as it appears to require less stress compared to the case without RDT.

The results discussed so far are the same, irrespective of the choice of the governing laws assumed. Figures 2 and 3 show qualitatively identical features, except that the dynamic slip displacement, sliding velocity, temperatures and dynamic stress drop values are different in absolute terms, as expected.

By looking at Tables 2 and 3, we can appreciate that while the DR law and RD law simulations show shorter recurrence times for rupture events governed by Configuration $\mathrm{B}$, the opposite occurs for the $\mathrm{CH}$ law simulations, which provide a longer seismic cycle for Configuration $\mathrm{B}$, compared to that for Configuration A. This result is discussed in more detail in Appendix A.

\subsection{Sensitivity study}

To quantitatively assess the role of the RDT, we focus on a fault governed by the $\mathrm{CH}$ law (Equation 5) and we change the value of parameter $c$, which modulates its importance in the equation of motion (Equation 3). We selected different values of $c$ by considering typical values of $G$ and $v_{S}$ for depths comparable with our hypocentral depth (see Equation 4).

Our numerical results clearly show that high values of $c$ entail low co-seismic displacement (see Figure 4a); from a physical viewpoint, this results in the simulated earthquake having a lower magnitude. Moreover, high $c$ values entail lower velocity peaks and higher velocity minima (Figure $4 b$ ), lower temperature changes (see Figure 4c), and smaller dynamic overshoots (see Figure $4 \mathrm{~d}$ ). These observations support our conclusion that the RDT significantly affects the system dynamics by promoting smaller and more frequent earthquakes.

We also explored the role of the critical velocity $\left(v_{c}\right)$. As mentioned in Section 2.3, $v_{c}$ formally establishes the relative influence of the dynamic regime on each repeated instability. Indeed, the RDT is considered in the equation of motion (Equation 3) only in the dynamic behavior of the system, which corresponds to velocities greater than the $v_{c}$. This is physically reasonable, as given the quasi-static stage of the 


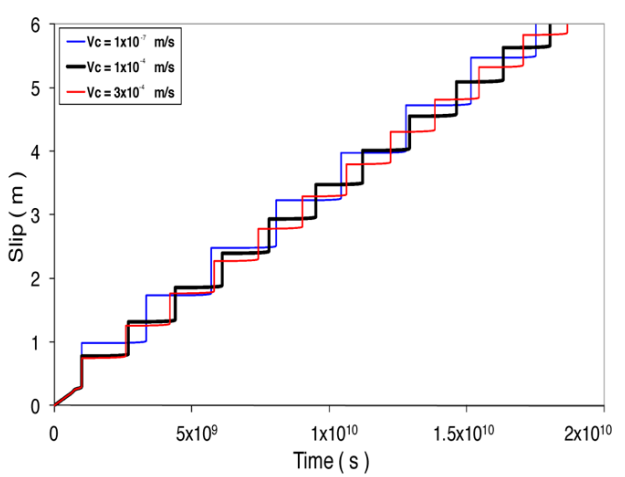

(a)

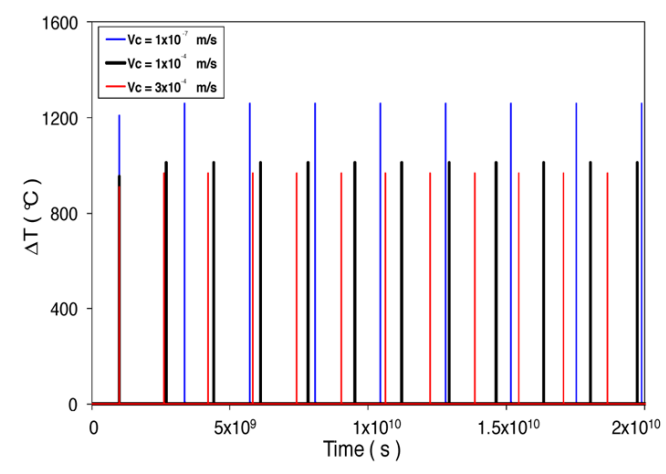

(c)

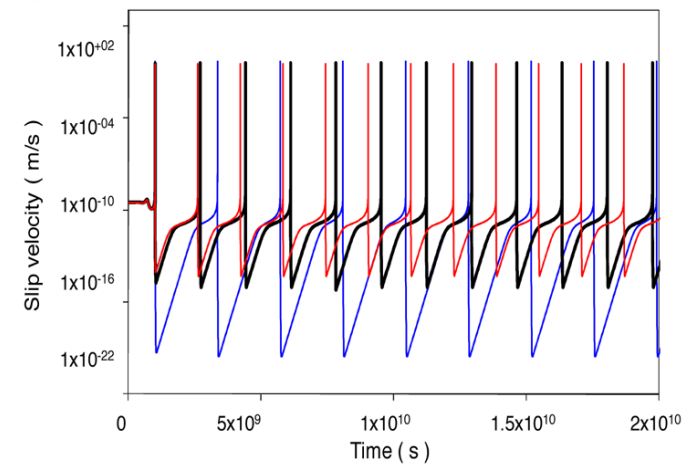

(b)

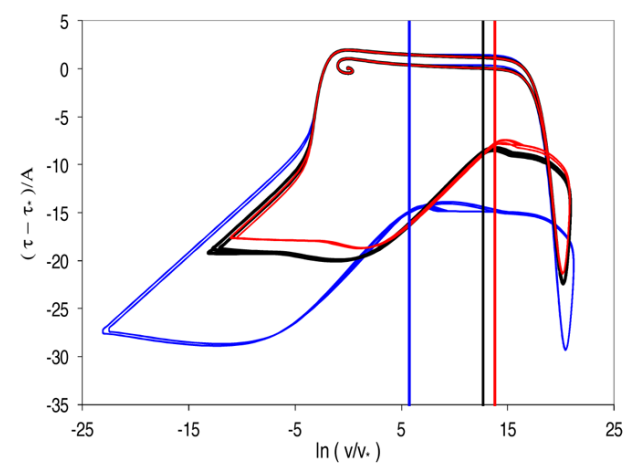

(d)

Figure 5. As for Figure 4, with changed $v_{c}$ and unchanged $c$, with respect to the reference value of Table 1. Black, reference configuration.

rupture, it is unlikely that energy is dissipated through seismic-wave emission. In Figure 5, we keep parameters $c$ unchanged (as in Table 1), but we vary $v_{c}$. It is apparent from Figure 5 that the critical velocity is a key parameter that can significantly affect the temporal recurrence of repeated earthquakes. Indeed, for those simulations where the critical velocity values are greater than the reference $v_{c}$ (Figure 5 , black lines ), we observe that the coseismic slip, the velocity peaks, and the temperatures developed decrease (Figure 5a$c$, red lines). The opposite occurs in the case of a smaller value of $v_{c}$ compared to its reference value (Figure $5 \mathrm{a}-\mathrm{c}$, blue lines). Referring to Figure $5 \mathrm{~d}$ and to Table 3 , we can also appreciate that the higher the critical velocity, the shorter the resulting seismic cycle.

In conclusion, we emphasize that the role of the RDT in the equation of motion (Equation 3) can strongly affect the earthquake rupture recurrence time for a large class of constitutive equations and for different degrees of fault instability. In addition, we wish to note the importance of our numerical experiments, which demonstrate that high values of both the RDT and the vc control dramatically shorten the seismic cycle.

\section{The $\mathrm{CH}$ law phase diagram}

If a physical system is not perturbed (i.e., an absence of stress perturbation effects due to another seismogenic fault), and if there is no occurrence of specific phenomena known to complicate earthquake cyclic patterns, such as wear production [Bizzarri 2010b] or the evolution of permeability and porosity [Bizzarri 2012b], the spring-slider system reaches its limit cycle [see Gu et al. 1984, Rice and Tse 1986, Belardinelli et al. 2003].

This section is aimed at detailing with the differences between the phase diagrams obtained for each of the constitutive laws. More specifically, a special phase diagram shape that occurred only for the $\mathrm{CH}$ law models, and was never observed for the other constitutive laws, emerged from the numerical simulations. Indeed, if we focus on Figures $3 \mathrm{~d}, 4 \mathrm{~d}$ and $5 \mathrm{~d}$, we can clearly observe that the $\mathrm{CH}$ law phase plane shows a 'figure-of- 8 ' shape, which is not present for the DR law model or the RD law model (Figures 1d, 2d) (see also figure 3 of Belardinelli et al. [2003]). In other words, focusing on the $\mathrm{CH}$ law numerical results, we can see from Figures $3 \mathrm{~d}, 4 \mathrm{~d}$ and $5 \mathrm{~d}$ that a point in the phase space $(\tau, v)$ is reached twice by the system trajectory during each single instability event.

In Figure 6, we have plotted an example of a $\mathrm{CH}$ law phase diagram that represents a single, generic limit cycle that was extracted from the whole simulation. We use a color scale to emphasize the temporal evolution of the dynamic system. In this case, a particular phase of the physical system can be associated with a particular portion of the limit cycle. As an example, we can easily understand that the fault analog system takes a very short time to enter the dynamic regime, to perform a seismic instability, and to decelerate to 


\begin{tabular}{|c|c|c|c|c|c|c|}
\hline \multirow[t]{3}{*}{ Parameter value } & \multicolumn{6}{|c|}{ Recurrence time (years) } \\
\hline & \multicolumn{2}{|c|}{ Dieterich-Ruina law } & \multicolumn{2}{|c|}{ Ruina-Dieterich law } & \multicolumn{2}{|c|}{ Chester and Higgs law } \\
\hline & Conf. A & Conf. B & Conf. A & Conf. B & Conf. A & Conf. B \\
\hline \multicolumn{7}{|l|}{$\begin{array}{l}\text { Parameter } c \text { in the RDT } \\
\left(v_{c}=1 \times 10^{-4} \mathrm{~m} / \mathrm{s}\right)\end{array}$} \\
\hline $2.700 \times 10^{6} \mathrm{~Pa} \mathrm{~s} / \mathrm{m}\left(^{*}\right)$ & 134.46 & 102.11 & 123.18 & 93.97 & 60.19 & 63.55 \\
\hline $3.375 \times 10^{6} \mathrm{~Pa} \mathrm{~s} / \mathrm{m}$ & 127.96 & 127.96 & 117.09 & 89.59 & 57.68 & 60.89 \\
\hline $4.500 \times 10^{6} \mathrm{~Pa} \mathrm{~s} / \mathrm{m}\left(^{*}\right)$ & 118.65 & 90.35 & 108.33 & 83.30 & 54.02 & 57.01 \\
\hline $5.400 \times 10^{6} \mathrm{~Pa} \mathrm{~s} / \mathrm{m}$ & 112.35 & 85.66 & 102.38 & 79.02 & 51.52 & 54.39 \\
\hline $8.500 \times 10^{6} \mathrm{~Pa} \mathrm{~s} / \mathrm{m}(*)$ & 96.30 & 73.71 & 87.15 & 68.05 & 45.00 & 47.47 \\
\hline \multicolumn{7}{|l|}{$\begin{array}{l}\text { Critical velocity } v_{c} \\
\left(c=4.5 \times 10^{6} \mathrm{~Pa} \mathrm{~s} / \mathrm{m}\right)\end{array}$} \\
\hline $3 \times 10^{-4} \mathrm{~m} / \mathrm{s}\left(^{*}\right)$ & 114.31 & 83.37 & 104.36 & 77.06 & 50.92 & 51.79 \\
\hline $1 \times 10^{-4} \mathrm{~m} / \mathrm{s}\left(^{*}\right)$ & 118.65 & 90.35 & 108.33 & 83.30 & 54.02 & 57.01 \\
\hline $1 \times 10^{-5} \mathrm{~m} / \mathrm{s}$ & 127.69 & 104.55 & 116.65 & 96.28 & 60.75 & 68.35 \\
\hline $1 \times 10^{-6} \mathrm{~m} / \mathrm{s}$ & 136.63 & 118.36 & 124.95 & 109.19 & 67.72 & 80.07 \\
\hline $1 \times 10^{-7} \mathrm{~m} / \mathrm{s}\left(^{*}\right)$ & 145.49 & 131.86 & 133.25 & 122.09 & 74.92 & 92.12 \\
\hline
\end{tabular}

Table 3. Recurrence times for the different governing laws and the two configurations listed in Table 1 resulting from the sensitivity study (see Section 3.2). Values reported in bold represent the reference configurations. Asterisks denote the simulations reported in Figures 4 and 5. Conf., configuration.

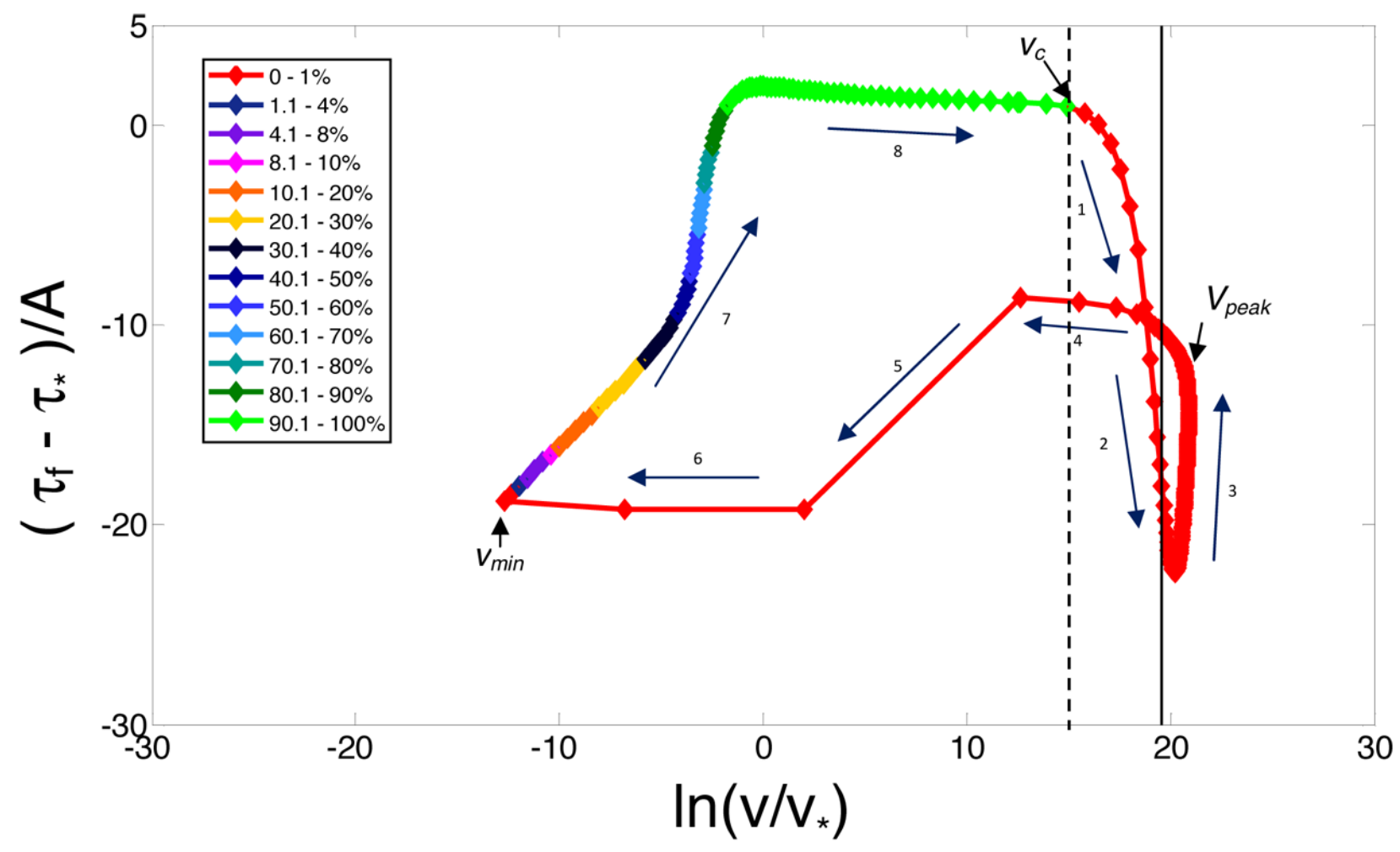

Figure 6. Single limit cycle resulting from the $\mathrm{CH}$ law and with the RDT. The parameters are those of Table 1. The colors express the relative duration of each single phase with respect to the total duration of the cycle. The count begins from the point marked by the symbol $v_{c}$ and proceeds clockwise. Dashed black line, $\ln \left(v_{c} / v_{*}\right)=12.7$; continuous black line, $\ln \left(v_{l} / v_{*}\right)=19.57$, which formally defines the time occurrence of a dynamic instability. 


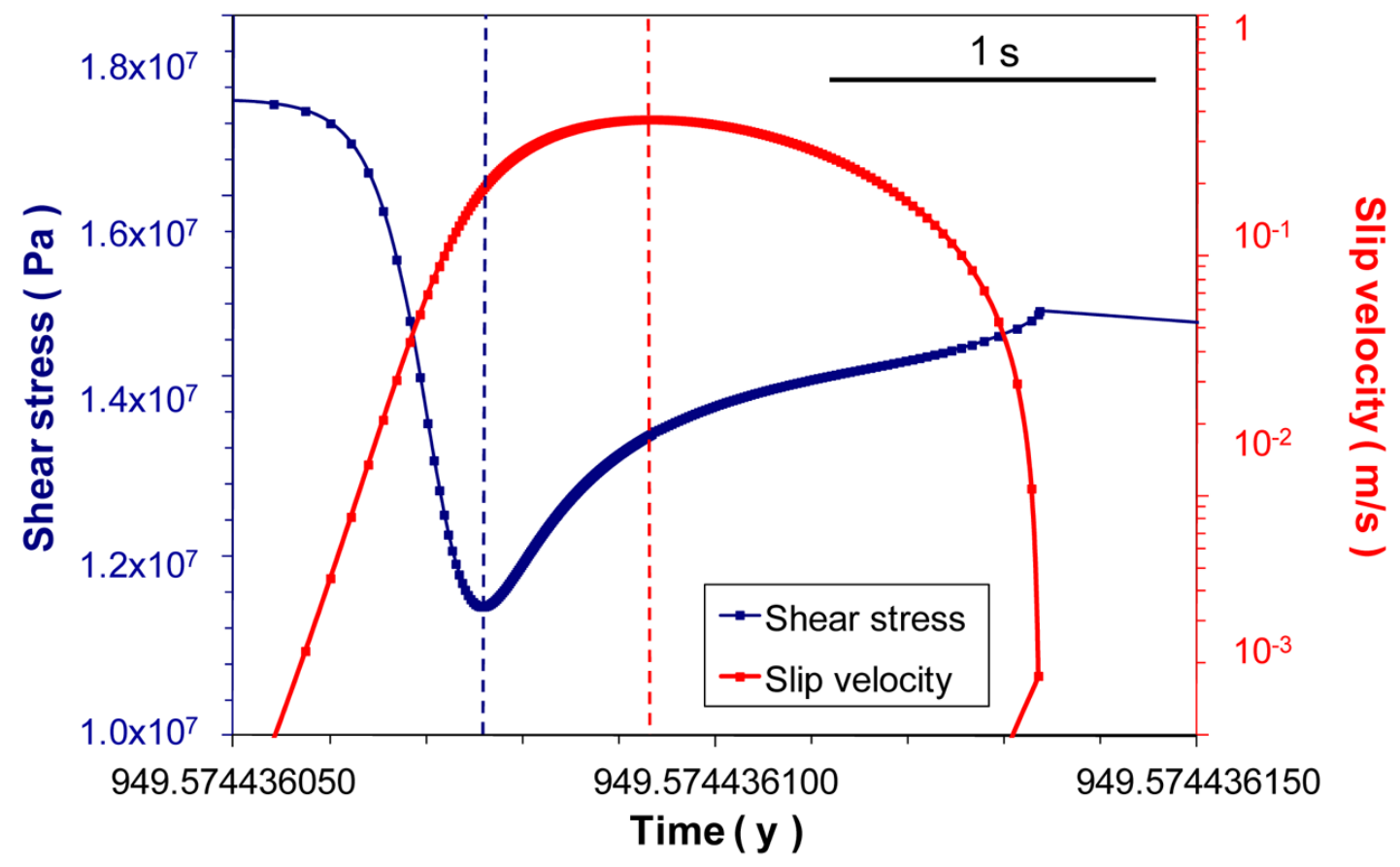

Figure 7. Superimposition of the slip velocity and the shear stress time histories, in the $\mathrm{CH}$ law case within a very narrow time window. The velocity peak is reached only a few instants after the shear stress minimum is achieved.

very low slip velocities. The fully dynamic phase of the seismic cycle is no more that $1 \%$ of the entire fault cycle (Figure 6 , red portion), as expected physically. Following the occurrence of a seismic instability episode (Figure 6, black vertical line), the system itself keeps on accelerating, even when the traction starts to rise. This fast restrengthening stage has already been observed by Bizzarri [2010a] in an extended fault model that obeys the $\mathrm{CH}$ constitutive law.

We can clearly see that the dynamic system runs through a rapid restrengthening phase just before reaching its peak: the shear stress reaches its minimum before the velocity attains its maximum value, $v_{\text {peak }}$. This is clearly shown in Figure 7, where the vertical dashed line indicates the minimum in $\tau$ (blue line) and the peak in $\mathrm{v}$ (red line). The same behavior has been reported in mechanical lubrication models [Bizzarri 2012c]. As discussed by Tinti et al. [2004], this result entails relevant seismological implications, in that we cannot use the $v$ time integration to retrieve the (equivalent) slip-weakening distance up to the time when $v_{\text {peak }}$ is attained, as suggested by Mikumo et al. [2003].

\section{Discussion and concluding remarks}

In the present study, we have modeled repeated instability events through a one-degree-of-freedom mass-spring fault analog model. The results obtained by using this analog fault model are appropriate to simulate the dynamic motion of a fault when a rupture propagates as a classical expanding crack, or when it is stopped by a strong barrier (for instance by a velocity strengthening region), when the material properties of the rupture surface are homogeneous, and when the spatial distribution of the stress on the fractured portion of the fault is either homogeneous or well represented by a spatial average. When these conditions are met, the springslider system is extremely effective in modeling repeated instabilities on the same fault structure (primarily because of its computational simplicity).

We have considered different governing laws in the RS friction framework; namely the DR law, the RD law and the $\mathrm{CH}$ law. The first two of these laws are 'canonical', in that they have been largely used in the previous literature. We have also considered the $\mathrm{CH}$ law because it is simply a (laboratory-based) extension of the RD law. We emphasize that besides having been the subject of previous studies [e.g., Marone 1998, Rubin and Ampuero 2005, 2009, Bizzarri 2011], a systematic comparison of the variety of formulations of the governing laws is certainly beyond the scope of the present study.

By conducting numerical simulations of seismic cycles, and by adopting different laboratory-derived friction laws and various physical configurations, we have essentially attained three key objectives. First, we show that including the RDT ( $c \dot{u}$ in Equation 3) dramatically affects the evolution of a spring-slider system cycle. In particular, the inclusion of the RDT induces a ca. $30 \%$ reduction in the recurrence time of subsequent instability events, with respect to the reference case (see Table 2). This reduction is a stable feature that does not depend on any specific governing law applied to the fault, nor on the fault instability level. Moreover, we show that the RDT entails a decrease (by ca. 27\%-30\%) in the co-seismic slip displacement that develops during each instability event (Figures 1a, 2a, 3a). At the same time, we can also observe the decreasing velocity peaks during a seismic instability event (Figures 1b, 2b, 3b), a drop in the developed temperature due to frictional heating (Figures 1c, 2c, 3c), and finally 
a dynamic overshoot reduction (Figures $1 \mathrm{~d}, 2 \mathrm{~d}, 3 \mathrm{~d}$ ). In particular, neglecting the seismic radiation (i.e., without the RDT) results in a complete overshoot, while adding the RDT, results in a reduction in the dynamic overshoot of ca. $44 \%$ (in the case of the DR law and the RD law; see Figures 1d, 2d) and of ca. $51 \%$ (in the case of the $\mathrm{CH}$ law; see Figure 3d). These values are consistent with the exact estimates given by McGarr [1994, 1999]; a simulation with inertia without RDT yields an overshoot of $1 / 2$, while the introduction of the RDT (still with inertia) results in a dynamic overshoot of ca. $1 / 4$ (so that the reduction is by a factor of 2; see also Savage and Wood [1971], Beeler [2001] and Segall [2010]).

Overall, this suggests that neglecting the RDT indicates stronger but less frequent earthquakes.

Secondly, we propose a parametric study aimed to show how different values of $c$ and $v_{c}$ can affect the simulated cycle of the $\mathrm{CH}$ law model. Our numerical experiments suggest that as long as values $c$ and the critical slip rate values $v_{c}$ (controls the system dynamic phase onset) increase (see Section 2.3 for further details), the duration of the seismic cycle decreases.

Thirdly, as a side result, we show a specific feature of the $\mathrm{CH}$ law model, which shows a phase diagram with a 'figureof-8'-shaped trajectory; in this case, a point in the phase space $(\tau, v)$ is reached twice for each instability event during the system evolution (see Figure 6). This phenomenon is closely related to the rapid restrengthening mechanism that occurs immediately after the dynamic stress release phase [see also Bizzarri 2010a]. This rapid restrengthening is intimately related to the frictional heating, which is, in turn, proportional to the degree of instability of the fault. Indeed, we have seen from Figure A1c that a more unstable configuration leads to more pronounced rapid restrengthening. This in turn results in a different cycle time value; we observed that with the $\mathrm{CH}$ law, the strong seismic configuration shows shorter recurrence times than less unstable configurations, contrary to the general behavior expected in cases when the temperature does not explicitly enter into the analytical expression of the governing model (such as the canonical DR law and RD law).

As an overall conclusion, we highlight that our data show the limits of the canonical, widely used, equation of motion formula for the 1-D spring-system, which neglects the RDT; i.e., the energy lost in seismic wave propagation. This contribution is inherently assumed in more elaborate 3D fault models [e.g., Bizzarri and Cocco 2005, Day et al. 2005, among many others], or it is introduced in the so-called quasi-dynamic 3-D models [e.g., Cochard and Madariaga 1994, Lapusta and Liu 2009]. On the contrary, this contribution has been largely ignored in the literature that relates to the 1-D mass-spring model, with some relevant exceptions [Xu and Knopoff 1994, Beeler 2001, Beeler et al. 2002, Beeler 2006, Bizzarri 2012a]. Undoubtedly, such an analog fault system is extremely efficient in modeling repeated instabilities on the same fault structure (primarily because of its compu- tational simplicity). However, our findings emphasize that the conventional equation of motion can lead to biased results (regardless of the choice of a specific fault constitutive equation), and that the RDT should be correctly included in numerical models with a mass-spring system. In particular, the dynamic overshoot obtained in the framework of a spring-slider system with inertia and with the RDT is comparable with that which results from 3-D models, and consistent with observations from natural earthquakes.

To conclude, we are aware that the spring-slider model cannot be regarded as a tool to obtain exact, deterministic earthquake predictions, and that even the concept of the seismic cycle is largely debated (see Bizzarri [2012d] and references therein for a thorough review of the subject). Nevertheless, the mass-spring model can provide some useful insight into a more elaborated (and realistic) extended fault model, provided the radiation loss is adequately included in the model.

Acknowledgements. The authors thank M. Loddo and S. de Lorenzo for constructive discussions and for their support. E. Fukuyama and Y. BenZion are kindly acknowledged for some comments on an early, preliminary version of the manuscript. We are indebted to N. Beeler for stimulating discussions related to the issue of the radiation damping term in the equation of motion of the 1-D fault model used here. Finally, we wish to thank two referees and the associate editor for their constructive comments.

\section{References}

Abe, Y., and N. Kato (2012). Complex earthquake cycle simulations using a two-degree-of-freedom spring-block model with a rate- and state-friction law, Pure Appl. Geophys.; doi:10.1007/s00024-011-0450-8.

Allen, R.M. (2007). Earthquake hazard mitigation: new directions and opportunities, In: G. Schubert (ed.), Treatise on Geophysics (Earthquake Seismology, ed. by H. Kanamori, vol. 4), Elsevier, 607-648.

Belardinelli, M.E., A. Bizzarri and M. Cocco (2003). Earthquake triggering by static and dynamic stress changes, J. Geophys. Res., 108, B02135; doi:10.1029/2002JB001779.

Beeler, N.M. (2001). Stress drop with constant, scale-independent seismic efficiency and overshoot, Geophys. Res. Lett., 28, 3353-3356.

Beeler, N.M., T.-F. Wong and T.E. Tullis (2002). Slip-weakening distance and fracture energy during dynamic sliding with laboratory-inferred fault strength, Proc. 2002 SCEC Meeting, Oxnard, CA, USA.

Beeler, N.M. (2006). Inferring earthquake source properties from laboratory observations and the scope of laboratory contributions to source physics, In: Radiated Energy and the Physics of Faulting, Geophysical Monograph Series (AGU) 170, 99-119.

Bizzarri, A., and M. Cocco (2005). 3D dynamic simulations of spontaneous rupture propagation governed by different constitutive laws with rake rotation allowed, Annals 
of Geophysics, 48 (2), 279-299.

Bizzarri, A., and M. Cocco (2006a). A thermal pressurization model for the spontaneous dynamic rupture propagation on a three-dimensional fault: 1 . Methodological approach, J. Geophys. Res., 111, B05303; doi:10.1029/2005 JB003862.

Bizzarri, A., and M. Cocco (2006b). A thermal pressurization model for the spontaneous dynamic rupture propagation on a three-dimensional fault: 2 . Traction evolution and dynamic parameters, J. Geophys. Res., 111, B05304; doi: 10.1029/2005JB003864.

Bizzarri, A., and M. Cocco (2006c). Comment on "Earthquake cycles and physical modeling of the process leading up to a large earthquake", Earth Planets Space, 58, 15251528.

Bizzarri, A. (2010a). Pulse-like dynamic earthquake rupture propagation under rate-, state- and temperature-dependent friction, Geophys. Res. Lett., 37, L18307; doi:10.1029/2010 GL044541.

Bizzarri, A. (2010b). On the recurrence of earthquakes: role of wear in brittle faulting, Geophys. Res. Lett., 37, L20315; doi:10.1029/2010GL045480.

Bizzarri, A. (2010c). Determination of the temperature field due to frictional heating on a sliding interface, INGV Technical Reports, 158, 1-16, ISSN 2039-7941.

Bizzarri, A. (2011). On the deterministic description of earthquakes, Rev. Geophys., 49, RG3002; doi: 10.1029/2011RG 000356

Bizzarri, A., P. Crupi, S. de Lorenzo and M. Loddo (2011). Time occurrence of earthquake instabilities in rate- and state-dependent friction models, INGV Technical Reports, 192, 1-20, ISSN 2039-7941.

Bizzarri, A. (2012a). Modeling repeated slip failures on faults governed by slip-weakening friction, Bull. Seism. Soc. Am., 102 (2), 812-821; doi:10.1785/0120110141.

Bizzarri, A. (2012b). Effects of permeability and porosity evolution on simulated earthquakes, J. Struct. Geol., 38, 243253; doi:10.1016/j.jsg.2011.07.009.

Bizzarri, A. (2012c). The mechanics of lubricated faults: Insights from 3-D numerical models, J. Geophys. Res., 117, B05304; doi:10.1029/2011JB008929.

Bizzarri, A. (2012d). What can physical source models tell us about the recurrence time of earthquakes?, Earth Sci. Rev., 115, 304-318; doi:10.1016/j.earscirev.2012.10.004.

Boatwright, J., and M. Cocco (1996). Frictional constrains on crustal faulting, J. Geophys. Res., 101, 13,895-13,909.

Brace, W.F., and J.D. Byerlee (1966). Stick-slip as mechanism for earthquakes, Science, 153, 990-992.

Brune, J.N. (1970). Tectonic stress and the spectra of seismic shear waves from earthquakes, J. Geophys. Res., 75, 49975009; doi:10.1029/JB075i026p04997.

Carlson, J.M., J.S. Langer and B.E. Shaw (1994). Dynamics of earthquakes fault, Rev. Modern Phys., 66, 657-670.
Chester, F.M., and H.G. Higgs (1992). Multimechanism friction constitutive model for ultrafine quartz gouge at hypocentral conditions. J. Geophys. Res., 97, B2, 1859-1870.

Cochard, A., and R. Madariaga (1994). Dynamic faulting under rate-dependent friction, Pure Appl. Geophys., 142, 419-445.

Day, S.M., L.A. Dalguer, N. Lapusta and Y. Liu (2005). Comparison of finite difference and boundary integral solutions to three-dimensional spontaneous rupture, J. Geophys. Res., 110, B12307; doi:10.1029/2005JB003813.

Dieterich, J.H. (1978). Presiesmic fault slip and earthquakes prediction, J. Geophys. Res., 83, 3940-3948.

Dieterich, J.H. (1979). Modeling of rock friction, 1, Experimental results and constitutive equations, J. Geophys. Res., 84, 2161-2168.

Gibowicz, S.J. (1998). Partial stress drop and frictional overshoot mechanism of seismic events induced by mining, Pure Appl. Geophys., 153, 5-20.

Gu, J.C., J.R. Rice, A.L. Ruina and S.T. Tse (1984). Slip motion and stability of a single degree of freedom elastic system with rate and state dependent fiction, J. Mech. Phys. Solids, 32, 167-196.

Kato, N., and T. Tullis (2001). Radiation damping as approximation to inertial term for dynamic slip, ACES/GEM Meeting, Maui, Japan.

Lapusta, N., and Y. Liu (2009). Three-dimensional boundary integral modeling of spontaneous earthquake sequences and aseismic slip, J. Geophys. Res., 114, B09303; doi: $10.1029 / 2008 J B 005934$.

Marone, C. (1998). Laboratory-derived friction laws and their application to seismic faulting, Annu. Rev. Earth Planet. Sci., 26, 643-646.

McGarr, A. (1994). Some comparisons between mining-induced and laboratory earthquakes, Pure Appl. Geophys., $142,467-489$.

McGarr, A. (1999). On relating apparent stress to the stress causing earthquake fault slip, J. Geophys. Res., 104, 30033011.

Mikumo, T., K.B. Olsen, E. Fukuyama and Y. Yagi (2003). Stress-breakdown time and slip-weakening distance inferred from slip-velocity functions on earthquake faults, Bull. Seismol. Soc. Am., 93, 264-282, doi:10.1785/012002 0082.

Molnar, P. (1979). Earthquake recurrence intervals and plate tectonics, Bull. Seism. Soc. Am., 69, 115-133.

Orowan, E. (1960). Mechanism of seismic faulting in rock deformation, Geol. Soc. Am. Mem., 79, 323-345.

Panza, G.F., Romanelli, F. and F. Vaccai (2001). Seismic wave propagation in laterally heterogeneous anelastic media: theory and applications to seismic zonation, Adv. Geophys. 43, 1-95.

Panza, G.F., Irikura, K., Kouteva, M., Peresan, A., Wang, Z. and R. Paragoni (2011). Advanced seismic hazard assess- 
ment, Pure Appl. Geophys. 169, 1-9; doi:10.1007/s00024010-0179-9.

Press, W.H., S.A. Teukolsky, W.T. Vetterling and B.T. Flannery (1992). Numerical recipes in C: The art of science computing, $3^{\text {rd }}$ ed., Cambridge University Press, New York.

Reid, H.F. (1910). The mechanics of the earthquakes, the California earthquake of April 18, 1906, report of the state investigation commission, 2, Carnegie Inst., Washington, D.C., USA.

Rice, J.R., and S.T. Tse (1986). Dynamic motion of a single degree of freedom system following a rate and state dependent friction law, J. Geophys. Res., 91, 521-530.

Rice, J.R. (1993). Spatio-temporal complexity of slip on a fault, J. Geophys. Res., 98, 9885-9907.

Rubin, A.M., and J.-P. Ampuero (2005). Earthquake nucleation on (aging) rate and state faults, J. Geophys. Res., 110, B11312; doi:10.1029/2005JB003686.

Rubin, A.M., and J.-P. Ampuero (2009). Self-similar slip pulses during rate-and-state earthquake nucleation, J. Geophys. Res., 114, B11305; doi:10.1029/2009JB006529.

Ruina, A.L. (1983). Slip instability and state variable friction laws, J. Geophys. Res., 88, 10,359-10,370, doi:10.1029/83 JB088.

Savage, J.C., and M.D. Wood (1971). The relation between apparent stress and stress drop, Bull. Seism. Soc. Am., 61, 1381-1388.

Segall, P. (2010). Earthquake and Volcano Deformation, Princeton Univ. Press, Princeton, N. J., 424 pp.

Tinti, E., A. Bizzarri, A. Piatanesi and M. Cocco (2004). Estimates of slip weakening distance for different dynamic rupture models, Geophys. Res. Lett., 31, L02611; doi: 10.1029/2003GL018811.

Xu, H.-J., and L. Knopoff (1994). Periodicity and chaos in a one-dimensional model of earthquakes, Phys. Rev. E., 50, 3577-3581.

Walsh, J.B (1971). Stiffness in faulting and in friction experiments. J. Geophys. Res., 76, 8597-8598; doi:10.1029/JB076 i035p08597.

Weeks, J.D. (1993). Constitutive laws for high-velocity frictional sliding and their influence on stress drop during unstable slip, J. Geophys. Res., 98, 17,637-17,648.

Wyss, M., A. Nekrasova and V. Kossobokov (2012). Errors in expected human losses due to incorrect seismic hazard estimates, Nat. Haz.; doi:10.1007/s11069-012-0125-5.

\footnotetext{
*Corresponding author: Andrea Bizzarri, Istituto Nazionale di Geofisica e Vulcanologia, Sezione di Bologna, Bologna, Italy; email: bizzarri@bo.ingv.it. 


\section{Appendix A}

In Section 3.1, we saw that when we assume the DR law or the RD law, the cycle time resulting from Configuration $\mathrm{A}$ is greater than that obtained with the parameters of Configuration $\mathrm{B}$, regardless of the adoption of the RDT (see also Table 2). This is clearly visible in Figures $1 \mathrm{~b}$ and $2 \mathrm{~b}$.

To better appreciate this result, we re-plotted Figures 1d, $2 \mathrm{~d}$ and $3 \mathrm{~d}$ without normalization (see Figure A1a, b, c, respectively), to avoid any possible masking effects due to normalization by constant $\mathrm{A}$, which is different in the two configurations. It is clear from Figure $A 1 a, b$ that in the strong seismic configuration (i.e., Configuration $A$ ) the stress release is greater than in Configuration $\mathrm{B}: \Delta \tau^{(\mathrm{A})}>\Delta \tau^{(\mathrm{B})}$ (this makes sense physically, since a more unstable fault is known to produce a greater stress drop). Moreover, the minimum velocity values are lower in Configuration A compared to those from Configuration B, especially in the case of the DR law simulation: $v_{\min }{ }^{(\mathrm{A})}<v_{\min }{ }^{(\mathrm{B})}$ (this is also clear from Figures $1 \mathrm{~b}$ and $2 \mathrm{~b})$. From these conditions $\left(\Delta \tau^{(\mathrm{A})}>\Delta \tau^{(\mathrm{B})}\right.$ and $\left.v_{\text {min }}{ }^{(\mathrm{A})}<v_{\min }{ }^{(\mathrm{B})}\right)$ we can see that at the end of the decelerating stage, the system has to recover more stress in the case of Configuration A than in the case of Configuration B. This is essentially the cause of the result $T_{\text {cycle }}{ }^{(\mathrm{A})}>T_{\text {cycle }}{ }^{(\mathrm{B})}$.

From Table 2 (and from Figure $3 \mathrm{~b}$ ), it emerges that the opposite occurs in the case of the simulations performed by adopting the $\mathrm{CH}$ law model, still regardless of the introduction of the RDT: $T_{\text {cycle }}{ }^{(\mathrm{A})}>T_{\text {cycle }}{ }^{(\mathrm{B})}$ (although the difference is relatively small). This apparent paradox can be solved by looking at Figure A1c; from this plot, we can clearly see that $\Delta \tau^{(\mathrm{A})}<\Delta \tau^{(\mathrm{B})}$ and this (small) difference causes $T_{\text {cycle }}{ }^{(\mathrm{A})}$ to be (slightly) greater than $T_{\text {cycle }}{ }^{(\mathrm{B})}$ with the $\mathrm{CH}$ governing law. At this point, a question emerges: why do we have $\Delta \tau^{(\mathrm{A})}<\Delta \tau^{(\mathrm{B})}$ with the $\mathrm{CH}$ law? This is essentially due to the explicit dependence of the temperature $T$ that appears in the analytical expression of the constitutive model (Equation 7). During the co-sesimic phase, the variations of $T$ are important, and they result in the very special shape of the phase diagram at high speeds (this issue is discussed in detail in Section 4). In the strong seismic case (i.e., Configuration A, red curves), after the rapid re-strengthening, the shear stress level is higher compared to that attained in Configuration B (blue curves). Correspondingly, the final shear stress level after the dynamic overshoot is greater in Configuration $\mathrm{A}$ than in Configuration B (so that we have $\Delta \tau^{(\mathrm{A})}<\Delta \tau^{(\mathrm{B})}$ ).
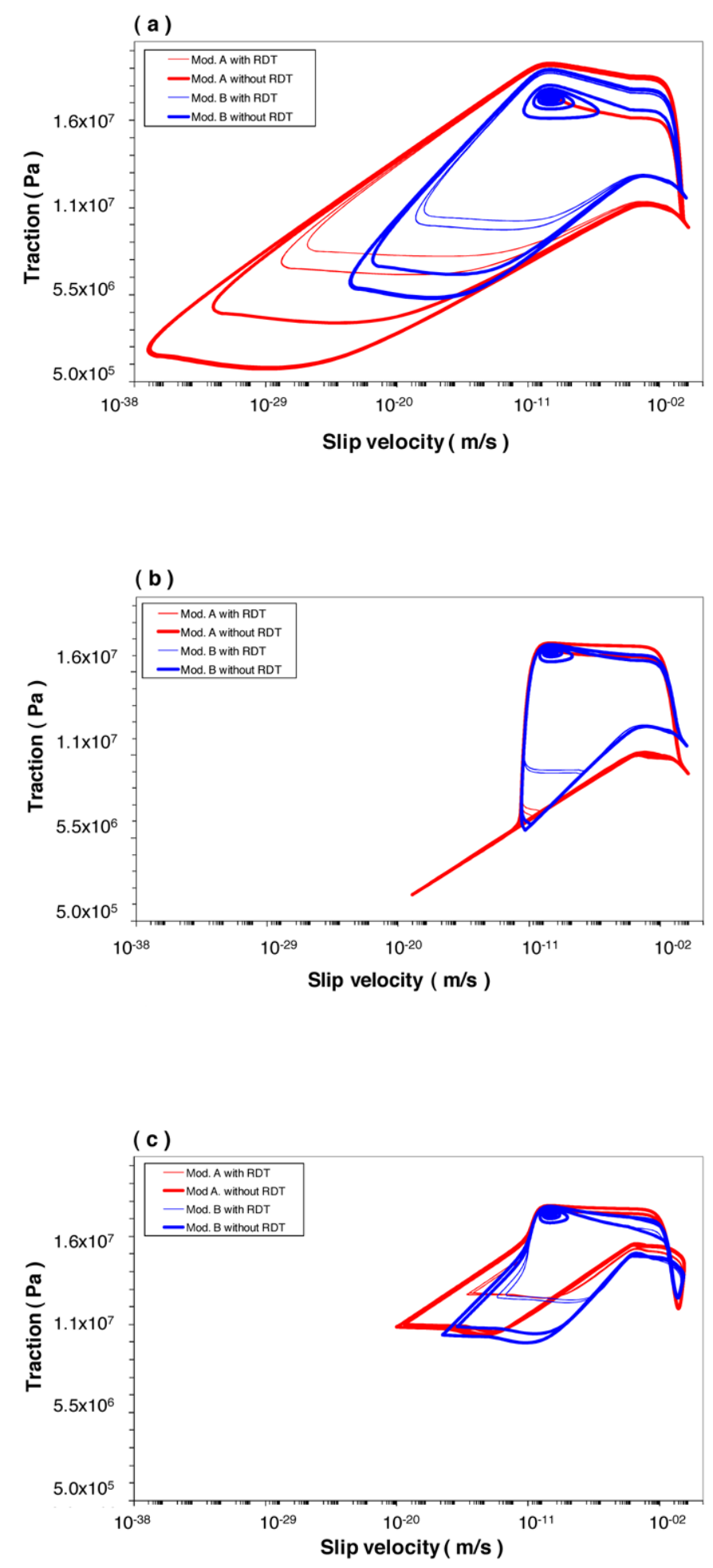

Figure A1. Phase diagrams without normalization for the reference configurations and for the three different governing models considered in this study. Panels (a), (b) and (c) correspond to Figures 1d, $2 \mathrm{~d}$ and $3 \mathrm{~d}$, respectively. 